\title{
Using a Complexity Approach to Study the Interpersonal Dynamics in Teacher-Student Interactions: A Case Study of Two Teachers
}

\author{
HELENA J. M. PENNINGS \\ Utrecht University (The Netherlands)
}

\begin{abstract}
In the present study, complex dynamic systems theory and interpersonal theory are combined to describe the teacher-student interactions of two teachers with different interpersonal styles. The aim was to show and explain the added value of looking at different steps in the analysis of behavioral timeseries data (i.e., observations of teacher and student behaviors) that are described by Warner (1998): (1) the general level and overall coordination, (2) the presence of linear, quadratic and cubic trends in behavior, (3) the coherence and phase in cyclical trends that are superimposed on the linear, quadratic and cubic trends, and (4) the residual fluctuations, when studying the fit between teacher and student interpersonal behavior. Interactional fit is conceptualized, and described in each step of the time-series analysis, using the principle of complementarity (e.g., Kiesler, 1996). Results showed that the teacherstudent interactions of the teacher with the most desirable interpersonal style largely followed the complementarity principle, whereas the interactions of the teacher with the less desirable interpersonal style did not. These results are discussed in light of the hypotheses and limitations of the study.
\end{abstract}

\section{Using a Complexity Approach to Study the Dynamics in Teacher-Student Interactions: A Case Study of Two Teachers}

Classroom management problems and problems with establishing productive teacherstudent relationships are often related to the teacher's interpersonal style (e.g., Wubbels, Brekelmans, Den Brok, \& Van Tartwijk, 2006). Classrooms are self-organizing systems that dynamically change over time, through interactions between its' elements (i.e., the teacher, the students, and the environment) (Hollenstein, 2013). The quality of the relationship between teachers and students is the developmental (macro-level) product of recurrent and cumulative (micro-level) interactions between the teachers and the class or individual students that occur in real-time (i.e., during lessons) (e.g., Kiesler, 1996; Koopmans \& Stamovlasis, 2016). According to Pincus et al. (2014), interactions between people can be 
understood as a process of subsequent events that unfold over time. Through verbal and non-verbal cues in such interaction, interaction partners form perceptions about each other's interpersonal behavior and style (e.g., Horowitz \& Strack, 2011; Kiesler, 1996). Based on those perceptions, an interaction partner reacts to the other person's actions, with behavior that fits these perceptions. Interpersonal behaviors of interaction partners become intertwined and adapt to each other in such a way that coordinated patterns in their interactions emerge (Pincus et al., 2014; Ramseyer \& Tschacher, 2016; Sadler, Ethier, Gunn, Duong, \& Woody, 2009).

Such coordination or fit is inherent to social interaction and mutually influences and constrains interaction partners' interpersonal behaviors and perceptions (Kiesler, 1996; Ramseyer \& Tschacher, 2016).

According to Warner (1991) people prefer coordinated interactions, and Ramseyer and Tschacher (2016) state that coordination or fit in interactions influences the quality of interactional outcomes, such as the quality of relationships. This means that the course of an interaction does not merely rely on the behavior of only the teacher or only the students (or class), but on (a) how well teacher and students' (or class') interpersonal behavior fits together, (b) how strongly their behaviors are interrelated or coordinated, and (c) the quality of their (initial) relationship.

Fit is therefore, an important aspect of interactions that should be studied, because interventions to change behavior and improve relationships should be aimed at the real-time interactions (Roorda, Koomen, Spilt, Thijs, \& Oort, 2013).

In the present study, the fit and coordination of interpersonal behaviors of two teachers interacting with their students are described, using insights from complex dynamic systems theory ${ }^{1}$ and interpersonal theory.

\section{Complex Dynamic Systems Theory}

Traditional approaches in social and behavioral sciences assume linear relations between different components of human behavior (e.g., Granic \& Hollenstein, 2003). These approaches heavily rely on assumptions of group homogeneity and central tendency. Individual (or dyadic) variability is seen as a nuisance rather than a source of information (Granic \& Hollenstein, 2003). Nevertheless, in more and more social scientific theories the nonlinear nature of change and development is being acknowledged. For example, one of the basic assumptions in e.g., interpersonal theory is that (moment-to-moment) interactions between people are never linear (Kiesler, 1996), but always nonlinear and cyclical (Kenny, Kashy, \& Cook, 2006; Kiesler, 1996).

Complex Dynamic systems (CDS) theorists are concerned with explaining and predicting nonlinear development. For example, explaining and predicting the development of social systems. People are dynamic social systems (Hollenstein, 2013), that develop through coordinated interactions with other social systems, that is individuals, dyads, groups, or the environment (e.g., Hollenstein, 2013).

According to CDS theory, interactions and development simultaneously take place on various hierarchically nested time-scales (Hollenstein, 2013): In real-time from second to second (i.e., micro-level time-scale), from hour to hour (i.e., meso-level time-scale), or in

\footnotetext{
I Complex Dynamic Systems Theory is also often referred to as Nonlinear Dynamic Systems theory, Chaos Theory, Complexity Theory, or Dynamic Systems Theory.
} 
developmental time like month to month or year to year (i.e., macro-level time-scale). Interactions between systems not only occur within time-scales but also between time-scales (Hollenstein, 2013), that is interactions on one time-scale affect interactions and development on another time-scale. Development of social systems (occurs through a process called selforganization (Koopmans \& Stamovlasis, 2016). Self-organization is a fundamental adaptive process in which social systems create and maintain 'order' through feedback loops and circularity causality (Koopmans \& Stamovlasis, 2016). Which means that elements of the (social) system in the micro-level time-scale mutually influence each other through interactions (e.g., interactions between teachers and students) (Hollenstein, 2013). From these interactions, a specific structure in the meso- and macro-level time-scale emerges (e.g., teacher-student relationship). At the same time, the structures that emerged and developed on the meso- or macro-level time-scale also affect and constrain the interactions on the micro-level time-scale (Hollenstein, 2013). The emerged behavior patterns are characterized by a few preferred states of modes of behavior (Hollenstein, 2013).

\section{Interpersonal Theory}

To describe and map interpersonal behavior and interpersonal styles researchers typically use interpersonal theory (e.g., Horowitz \& Strack, 2011; Kiesler, 1996). In which two orthogonal dimensions, Agency and Communion, are used to describe interpersonal behavior and styles. Another important aspect of interpersonal theory is the principle of complementarity.

\section{Agency and Communion}

According to interpersonal theory all interpersonal behaviors and styles can be captured as distinct combinations, or blends, of only two orthogonal dimensions of interpersonal behavior: Agency and Communion ${ }^{2}$ (e.g., Horowitz \& Strack, 2011; Kiesler, 1996). To characterize a person's macro-level interpersonal style, the position on the Agency dimension manifests in strivings for a certain degree of power or control (or lack thereof), and the position on the Communion dimension manifests in strivings for a certain degree of friendliness and affiliation (or lack thereof) (e.g., Horowitz \& Strack, 2011; Kiesler, 1996). On a micro-level, this often results in interpersonal behaviors that share similar levels of Agency and Communion characterizing their interpersonal style (compare to the preferred states or modes of behavior, Hollenstein, 2013). While interacting, interaction partners constantly negotiate how agentic and communal they need to be with each other (Kiesler, 1996), the quality of their relationship is then related to how those levels of agency and communion in interpersonal interactions fit together. To describe this fit the principle of complementarity (e.g., Kiesler, 1996) can be used.

\section{The Principle of Interpersonal Complementarity}

The two interpersonal dimensions can be used to describe the directions in which complementarity theoretically transpires. On the Agency dimension, complementarity occurs when interaction partners behave opposite in Agency (i.e., dominance induces submission, and vice versa). On the Communion dimension complementarity occurs when interaction partners behave similar in Communion (hostility begets hostility and friendliness

\footnotetext{
2 The terms Agency and Communion are meta-labels and depending on the context the two dimensions can be given different names (e.g., Horowitz \& Strack, 2011).
} 
begets friendliness) (e.g., Kiesler, 1996; Sadler et al., 2011). In general, it is claimed that when interactions largely follow the principle of complementarity this is related to the quality of the relationship between interaction partners (e.g., Kiesler, 1996). In practice, interactions often do not follow this complementarity principle (e.g., see a review by Orford, 1986). Orford (1986) suggested that status differences may be related to degree of complementarity in interactions. Also, according to Thijs, Koomen, Roorda, and Ten Hagen (2011), teachers are trained professionals that are expected to sometimes inhibit the tendency to react with complementarity to behavior of students. For example, in situations where students are very hostile and dissatisfied towards the teacher, a hostile and dissatisfied reaction of the teacher may worsen or escalate the situation, whereas reacting with more leading or understanding behavior (i.e., high in both Communion and Agency), may bend the situation into a more positive direction. Pennings (2017) indeed found that teachers with more desirable teacherstudent relationships, more often refrained from reacting with complementarity to hostile student behavior than teachers with less desirable teacher-student relationships.

\section{The Present Study}

In the present study insights from CDS theory and interpersonal theory are combined to describe differences in how teacher and student real-time interpersonal behaviors fit together and how those differences are related to the teacher's interpersonal styles.

Fit in interactions will be described on a more general level, as well as how it temporally changes throughout the course of the interactions. The aim of the present study is to show and explain the added value of looking at different steps in the analysis of teacher-student interactions as behavioral time-series data, that are described by Warner (1998), to study the fit between teacher and student interpersonal behavior. Those different steps include: describing (1) the general level and overall coordination, (2) the presence of linear, quadratic and cubic trends in behaviors, (3) the coherence and phase in cyclical trends that are superimposed on the linear, quadratic and cubic trends, and (4) the residual fluctuations in the data.

In each step of the time-series analysis fit will be described in terms of the principle of complementarity. Since, it is assumed that complementarity is related to good relationships (e.g., Kiesler, 1996), it is expected that, the degree of complementarity will be higher in the interactions of the teacher with the most desirable interpersonal style (in terms of student outcomes, see Wubbels et al., 2006) than in those of the teacher with the less desirable interpersonal style.

In addition, it expected that both teachers will be able to refrain from the principle of complementarity, especially in Communion, when faced with hostile and dominant student behavior. Because Kiesler (1996) and Orford (1986) assume that departing from the principle of complementarity mainly happens in hierarchical relationships, (e.g., teacher-student relationships) and Thijs et al. (2011) argue that this is the result of their professional role and training. 


\section{Method}

\section{Design and Participants}

This study is a multiple case-study that focusses on two teachers with distinct interpersonal styles. Recordings of a lesson were made with one camera positioned in the back of the classroom (filming the teacher) and one camera in front of the classroom, (filming the students). At the end of the lesson students filled out a questionnaire to measure their teacher's interpersonal style.

The teachers whose interactions were described in this study are Ethan and Sam. Both teachers are male early career teachers with full-time jobs. Ethan is a 24-year-old Chemistry and Science teacher; he has two years of teaching experience. During the observed lesson, he teaches chemistry to an $8^{\text {th }}$ grade, senior general secondary class of 20 students. According to the students in this classroom Ethan has a helpful interpersonal style (i.e., scores of .31 on Agency and .40 on Communion). Sam is a 52-year-old Mathematics and Science teacher, he has one year of teaching experience. During the observed lesson, he teaches Mathematics to a $9^{\text {th }}$ grade, preparatory secondary vocational class of 22 students. According to the students in this classroom Sam has a struggling interpersonal style (i.e., scores of -.08 on Agency and -.12 on Communion).

\section{Instruments}

\section{Teacher Interpersonal Style}

Student perceptions of their teacher's interpersonal styles were measured with the Dutch 24item Questionnaire on Teacher Interaction (QTI; e.g., Wubbels, et al., 2006). Examples items are "This teacher has humor", and "This teacher is dissatisfied". Every item is rated on a five-point scale $(1=$ "never" and $5=$ "always") and loads on both interpersonal dimensions. Agency and Communion scores were derived by weighting the items based on their position on the Interpersonal Circle (Locke, 2011) and the octant representing the teacher's interpersonal style was derived by calculating the angular position of Agency and Communion scores in the IPC (Gurtman, 2011).

The circumplex structure (Browne's circular stochastic process model) underlying the data was studied using a larger dataset (i.e., from which Ethan and Sam are selected) and tested with CIRCE (Grassi, Luccio, \& Di Blas, 2010). The results showed satisfactory model fit for individual student perceptions $(\chi 2(28, N=18,424$; of each classroom one student was chosen at random $)=64917.46 ; p<.01$, RMSEA $=0.043$; CFI $=.99$, TLI $=.97$; Pennings et al., 2014). The reliability analysis for the two teacher's class aggregated scores showed sufficient reliability, Cronbach's $\alpha$ for Agency was .79 and for Communion Cronbach's $\alpha$ was .89. Class consensus (ICC ( $\mathrm{k}=$ class size); Lüdtke, Robitzsch, Trautwein, \& Kunter, 2009) was good for both teachers: for Ethan's class ICC $(\mathrm{k}=20)$ was .968 for Agency and .956 for Communion, for Sam's class ICC $(k=22)$ was .971 for Agency and .960 for Communion.

\section{Continuous Coding}

To study interpersonal adaptation in classrooms, we followed the approach used by Sadler and colleagues (e.g., Sadler et al., 2009; Lizdek, Woody, Sadler, \& Rehman, 2016), called Continuous Assessment of Interpersonal Dynamics (CAID) ${ }^{3}$. Using this approach,

\footnotetext{
3 The joystick-monitoring software program for CAID is available via www.wlu.ca/science/psadler
} 
interpersonal behavior is coded as a continuous flow of Agency and Communion as it unfolds over time.

The default settings of the CAID software were used: behavior coordinates are recorded every half-second, and coordinates range from $-1000=$ very low Agency/Communion to $+1000=$ very high Agency/Communion (i.e., to ensure maximum sensitivity of the computer joystick device) ${ }^{2}$.

Each teacher and student video was coded by two trained observers. Agency and Communion in teacher and students' behavior were coded to represent the class-level dynamics (cf. individual-level dynamics). This means that when behavior of the teacher was coded, observers took a shared student perspective. When the behavior of the class of students was coded, observers took a teacher perspective and pooled Agency and Communion in students' behavior. Individual teacher-student interactions were not considered, because, during the first 10 minutes of a lesson, a teacher mainly addresses the entire classroom (i.e., if individual interaction occurred those were very short, and affecting the entire class, e.g., small corrections to get the student's attention).

Inter-rater reliability (intra class correlations, ICC(2)) indicated strong agreement between the observers (LeBreton \& Senter, 2008). For Ethan, teacher Agency $\alpha=.73$, for teacher Communion $\alpha=.94$, for student Agency $\alpha=.95$, and for student Communion $\alpha=.92$. For Sam, teacher Agency $\alpha=.77$, for teacher Communion $\alpha=.83$, for student Agency $\alpha=.73$, and for student Communion $\alpha=.84$.

The ratings of Agency and Communion were aggregated for the two observers at each time point. This resulted in for time-series, two representing teacher interpersonal behavior and two representing student interpersonal behavior. Since the trajectories are exactly synchronized in time, they can be combined to study moment-to-moment coordination of interpersonal teacher and student behaviors.

\section{Analysis}

In analyzing the data, four steps of time-series analysis described by Warner (1998) were followed. The first step was to study the overall level and coordination in teacher and student Agency and Communion (i.e., by calculating averages and correlations). The second step was to study the presence of linear, quadratic, and cubic trends in the time-series (i.e., using ordinary least squares regression analysis). The third step was to study the presence of cycles that are superimposed upon trends (i.e., using (cross-) spectral analysis). The last step was to study the random variation after all linear, quadratic, cubic, and cyclical trends are removed from the data.

\section{Results}

\section{Overall Level and Coordination}

In Table 1, information on the level (i.e., mean) and variation (i.e., standard deviation) of teacher and student Agency and Communion in both classrooms are provided. The levels for Ethan and Sam differ. Ethan shows much more Communion and Agency, this means that, on average, he is quite dominant as well as friendly towards the students. Whereas for Sam's, his Agency and Communion scores are both negative, which means, that he, on average, is quite submissive and unfriendly towards the students. Ethan's students are one average very friendly and quite submissive. Sam's interactions with students, on average, are also 
consistent with the principle of complementarity. Similarly, to Sam, his students are somewhat unfriendly, and in contrary to Sam, his students are quite dominant.

Overall coordination (i.e., cross-correlation between the 1,176 measurements of the teacher and the students of a classroom), for Ethan's classroom was .71 for Communion and .86 for Agency, which is consistent with the principle of interpersonal complementarity (i.e., negative for Agency and positive for Communion). For Sam's classroom, overall coordination was -.39 for Communion and -.06 for Agency, which on the Communion dimension is not consistent with the complementarity principle, and on the Agency dimension very weakly consistent with the complementarity principle.

Table 1. Summary statistics for Level, Variation, and Overall coordination of Ethan's, Sam's, and their students' time-series

\begin{tabular}{|c|c|c|c|c|c|c|c|c|}
\hline & \multicolumn{4}{|c|}{ Communion } & \multicolumn{4}{|c|}{ Agency } \\
\hline & \multicolumn{2}{|r|}{ Ethan } & \multicolumn{2}{|r|}{ Sam } & \multicolumn{2}{|c|}{ Ethan } & \multicolumn{2}{|r|}{ Sam } \\
\hline & Teacher & Students & Teacher & Students & Teacher & Students & Teacher & Students \\
\hline Level (M) & 304 & 627 & -25 & -61 & 466 & -258 & -28 & 167 \\
\hline Variation $(S D)$ & 170 & 141 & 181 & 196 & 326 & 458 & 273 & 260 \\
\hline $\begin{array}{l}\text { Overall } \\
\text { Coordination }\end{array}$ & \multicolumn{2}{|r|}{.71} & \multicolumn{2}{|r|}{-.39} & \multicolumn{2}{|r|}{-.86} & \multicolumn{2}{|r|}{-.06} \\
\hline
\end{tabular}

Looking at the levels, variation, and overall coordination does not provide us with information about (nonlinear) changes in behavior throughout the lesson. Therefore, it is necessary to look at trends and cyclical patterns in the time-series. First, I will show the information provided by looking at visualizations of the time-series.

\section{Visual Inspection of the Time Series}

In Figure 1 and Figure 2, the bivariate time series of, respectively, Ethan and Sam and their students are presented; with along the x-axis time in half-seconds, and Agency and Communion are presented along the y-axis. For Ethan (Figure 1), the levels of teacher and student Communion tend to increase and decrease together, and for the most part Ethan's Communion is comparable to his students' Communion. In terms of complementarity, this indeed indicates sameness. Concerning Agency, when Ethan's level of Agency is higher his students' level of Agency is lower, and vice versa. In terms of complementarity this indeed indicates oppositeness.

This visual inspection provides extra information, because the levels and overall coordination indicated Ethan's and his students' behaviors to follow the complementarity principle. Yet, these visualizations also show, that Ethan and his students reciprocally change in their levels of Agency, indicating a turn-taking pattern in their interaction. Which, however, could not be detected from the overall levels and coordination provided in Table 1.

Sam's time series (Figure 2) show a somewhat different pattern. For communion, deep troughs in Sam's behavior can be observed, indicating moments where Sam is quite unfriendly. The students do not necessarily follow with negative behavior, but in general their behavior is not very friendly nor unfriendly. The overall levels that indicated complementarity on the communion dimension, failed to show these deep troughs of Sam's behavior together with rather stable Communion behavior of his students. It can also be seen 
from Figure 2, that Sam's level of Agency fluctuates quite a lot throughout the interaction, and that his students' Agency changes more gradually, and halfway, even shows some submissiveness, which then quickly changes towards dominant behavior again. This is also a pattern that the overall levels and coordination failed to grasp.

From these Figures, it is possible to describe the teacher's ability to refrain from hostile student behavior. For example, that Ethan does not face any hostile student behavior during these ten minutes of observation. Both Ethan and his students remain quite friendly throughout the entire interaction. For Sam we can see, that during the first 1.5 minutes the students become unfriendly, after a while, Sam becomes unfriendly too, his level of friendliness keeps on fluctuating from neutral to unfriendly, even though his students' friendliness remains quite stable. Thus, Sam seems not able to refrain from hostile behavior, and could even be the catalyst of negative interactions.
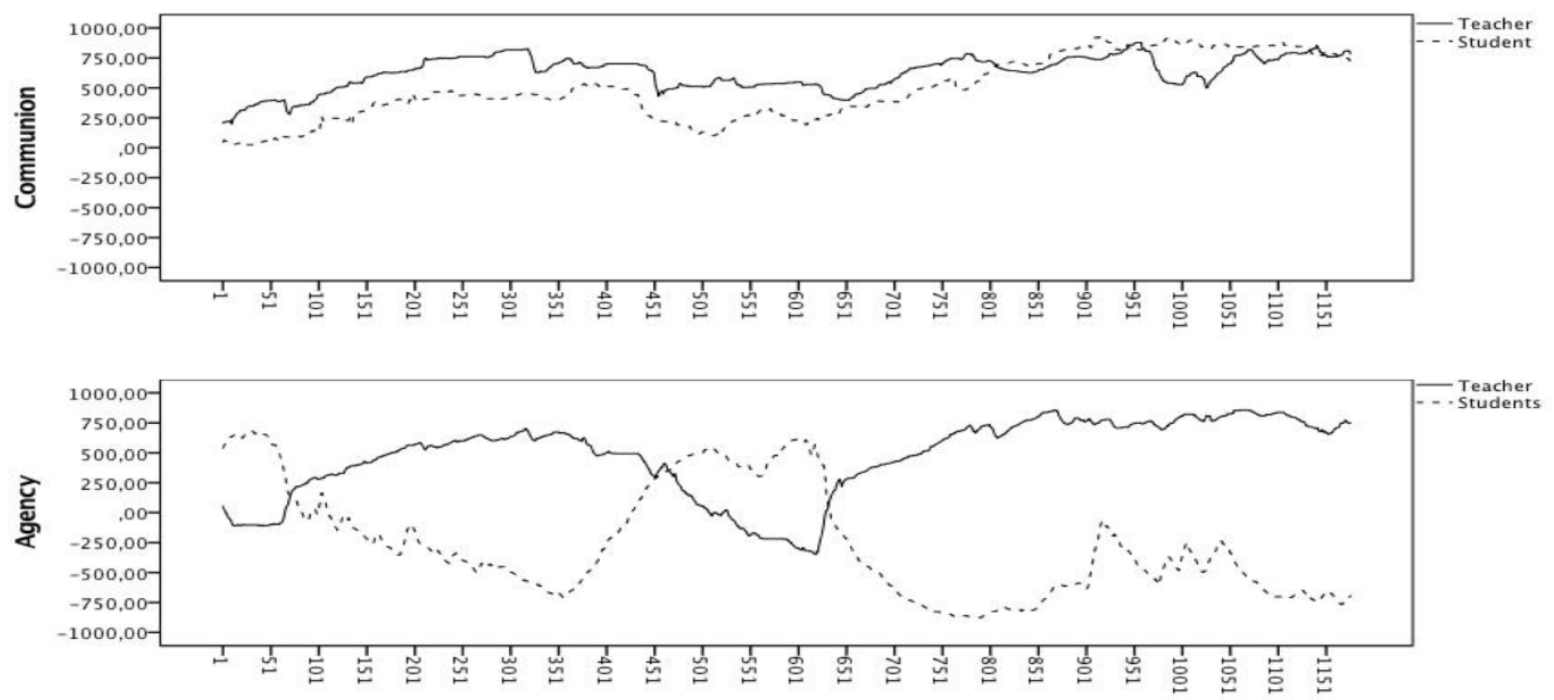

Figure 1. Time series for Agency and Communion of Ethan and his students 

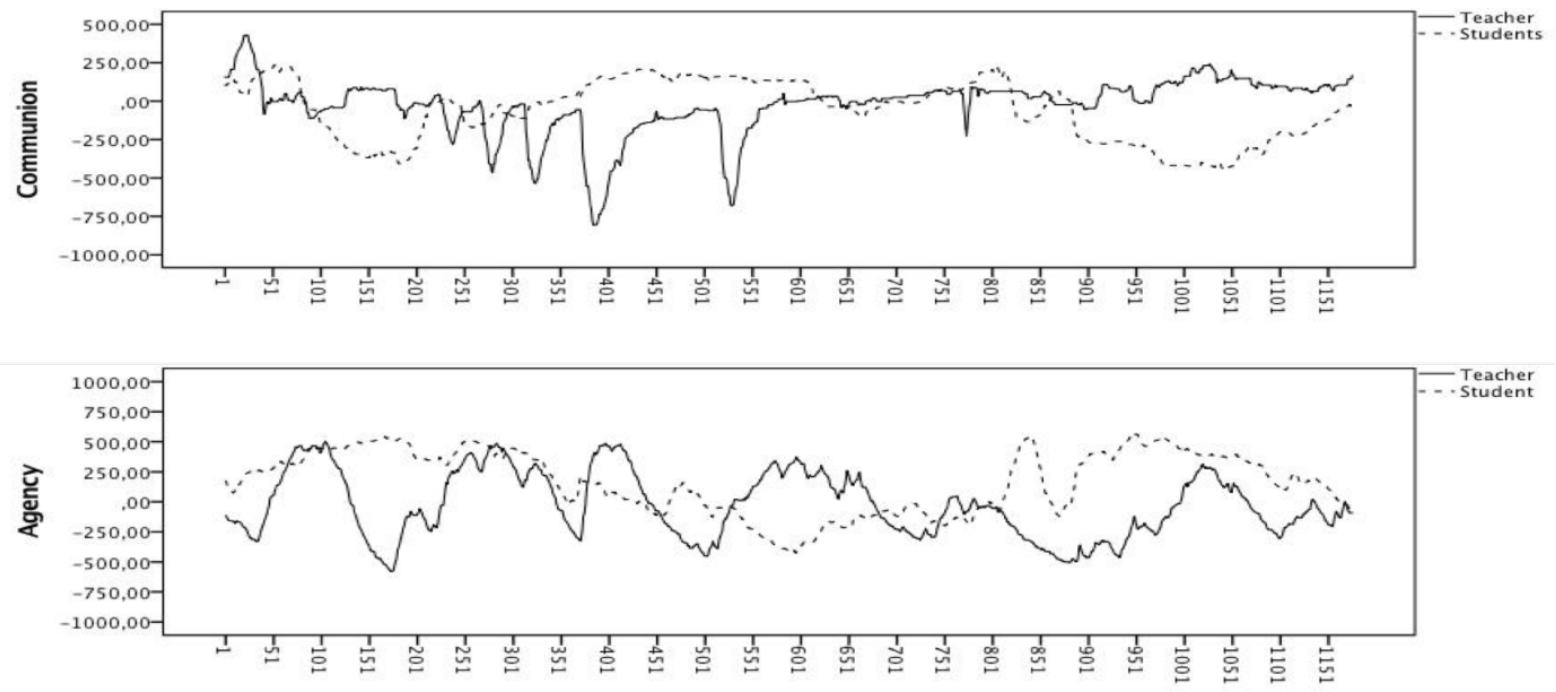

Figure 2. Time series for Agency and Communion of Sam and his students

\section{Trend Analysis}

Then the presence of linear, quadratic (i.e., curvilinear with one bend) and cubic (i.e., curvilinear with two bends) trends in teacher and student behavior was tested. In Table 2, information on the size and significance of the proportion of explained variance after adding (1) a linear term ( $R^{2}$ linear), (2) a quadratic term $\left(\Delta R^{2}\right.$ quadratic), and (3) a cubic term $\left(\Delta R^{2}\right.$ cubic) is provided.

Both for Ethan and Sam, the quadratic and/or the cubic terms significantly improved the linear model. This also shows the importance of studying the nonlinearity. In Figure 3, I provided the cubic model to show how the teacher's and their students' behaviors change throughout the interactions.

For Ethan, his and his students' levels of Agency and Communion in the beginning of the lesson were quite similar. Ethan increases in Communion quite strongly at first, but gradually stabilizes after a while. His students become more communal throughout the first ten minutes as well. For Agency, while Ethan becomes more Agentic, his students become less Agentic throughout the first ten minutes. In both cases this process starts off quite gradually and becomes steeper towards the end. Both patterns for Agency and Communion in Ethan's classroom indicate complementarity.

Table 2. Trends in the two Teacher's and their Students' Time Series

\begin{tabular}{|c|c|c|c|c|c|c|}
\hline & \multicolumn{3}{|c|}{ Teacher } & \multicolumn{3}{|c|}{ Student } \\
\hline & $\begin{array}{c}\mathrm{R}^{2} \\
\text { linear }\end{array}$ & $\begin{array}{l}\Delta \mathrm{R}^{2} \\
\text { quadratic }\end{array}$ & $\Delta \mathrm{R}^{2}$ cubic & $\begin{array}{r}\mathrm{R}^{2} \\
\text { linear }\end{array}$ & $\begin{array}{c}\Delta \mathrm{R}^{2} \\
\text { quadratic }\end{array}$ & $\Delta \mathrm{R}^{2}$ cubic \\
\hline Ethan's & $.238^{* * *}$ & $.004^{*}$ & $.187^{* * *}$ & $.685^{* * *}$ & $.029^{* * *}$ & $.004^{* * *}$ \\
\hline $\begin{array}{c}\text { Communion } \\
\text { Ethan's }\end{array}$ & $.278^{* * *}$ & $.038^{* * *}$ & $.027^{* * *}$ & $.255^{* * *}$ & .000 & $.013^{* * *}$ \\
\hline $\begin{array}{l}\text { Agency } \\
\text { Sam's }\end{array}$ & $.094^{* * *}$ & $.209^{* * *}$ & $.180^{* * *}$ & $.123^{* * *}$ & $.182^{* * *}$ & $.002^{* * *}$ \\
\hline $\begin{array}{l}\text { Communion } \\
\text { Sam's Agency }\end{array}$ & $.081^{* * *}$ & .001 & $.067^{* * *}$ & $.022^{* * *}$ & $.296^{* * *}$ & .000 \\
\hline
\end{tabular}


For Sam, we see a different pattern. In the beginning, he is quite Communal but his students are not. While his Communion decreases, his students' Communion increases somewhat, but remains very neutral. Sam's Communion increases again, but after a while, both his and his students' level of Communion decreases again. For Agency, in the very beginning of the lesson, Sam is not very agentic but his students are, while he increases in Agency the students' level of Agency decreases, towards a point where their level of Agency is similar. After which the students' level increases again, and the Sam's Agency somewhat decreases, but then follows the students. Throughout the whole ten-minute period, Sam's Agency seems lower than his student's Agency. The interaction patterns in Sam's classroom show that for the first seven minutes his interaction shows oppositeness on the Communion dimension, and almost the entire ten minutes his interactions show sameness on the Agency dimension, which means his interactions show a pattern of anti-complementarity.

\section{Cyclical Patterns}

Spectral- and cross-spectral analysis (SPSS-SPECTRA, version 24) were used to study the extent to which teacher and student Agency and communion contain cyclical patterns (i.e, sinusoidal curves) that occur superimposed on the linear, quadratic, and cubic trends. To perform spectral analysis, the linear, quadratic, and cubic trends were removed from the data, using ordinary least squares regression analysis. Then several measures were derived from the Spectral analysis results (for an elaborate description of the calculations see Warner, 1998). The measures are presented in Table 3.
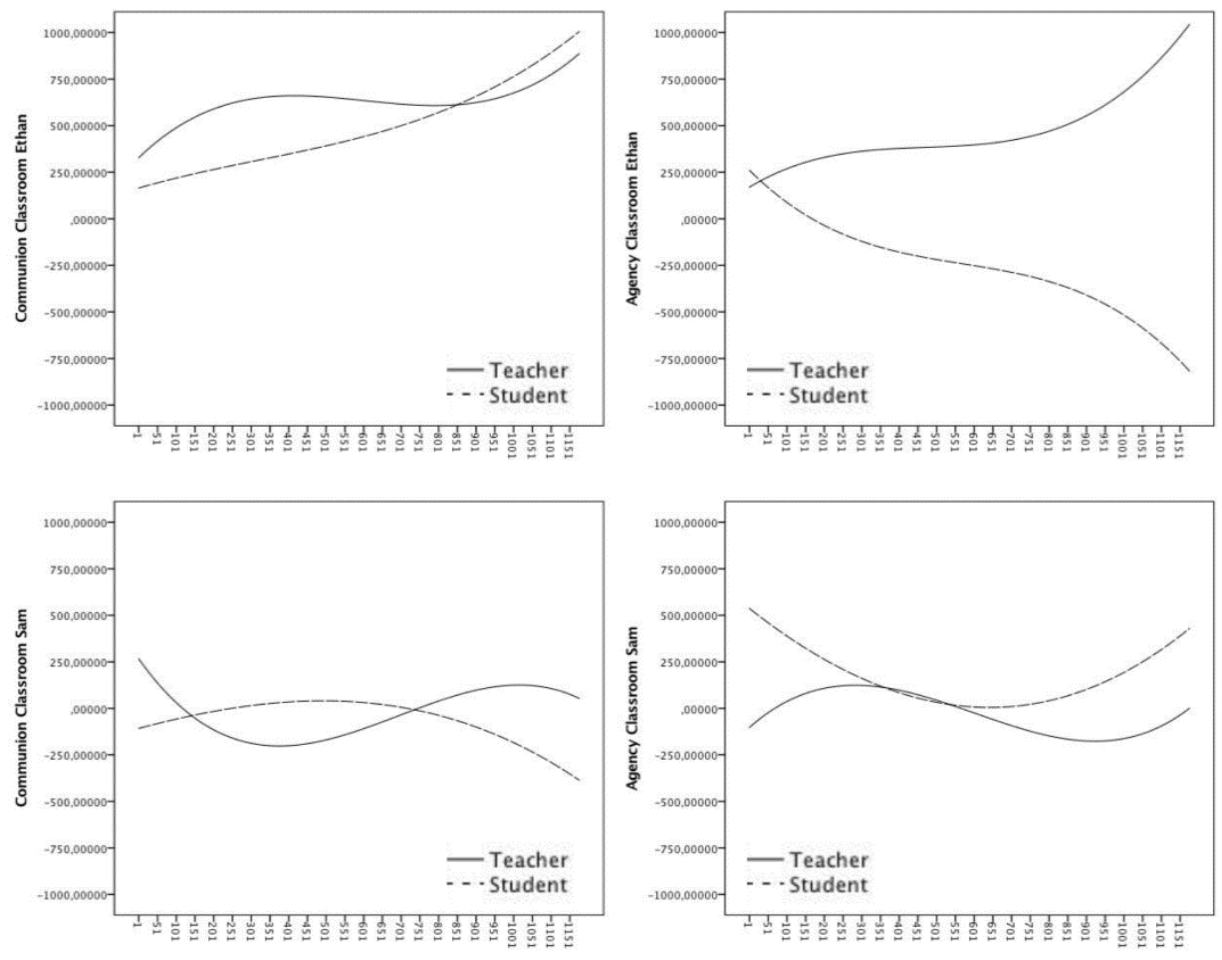

Figure 3. Trends in teacher and student Agency and Communion 
Table 3. Results for (Cross-) Spectral Analyses of Teacher and Student Time Series

\begin{tabular}{lcccc}
\hline & \multicolumn{2}{c}{ Communion } & \multicolumn{2}{c}{ Agency } \\
\cline { 2 - 5 } & Ethan & Sam & Ethan & Sam \\
\hline Teacher rhythmicity & .82 & .52 & .96 & .91 \\
Student rhythmicity & .94 & .92 & .94 & .91 \\
Average weighted coherence & .88 & .14 & .85 & .13 \\
Average weighted phase & .02 & .44 & .46 & -.44 \\
\hline
\end{tabular}

The Index of rhythmicity indicates how well the time series are represented by cyclical patterns. An index of rhythmicity higher than .80 indicates the presence of a reasonably regular cyclical patterns (Sadler et al., 2009). It can be seen from Table 4, that for Ethan, all rhythmicity values are larger than .80, and for Sam only rhythmicity in Communion is less well represented by cyclical patterns. But the Fisher test ( $\mathrm{p}<.05$, Warner, 1998), showed that the recurrent cycles were significant for all time-series.

Then the degree of synchronization of cyclical patterns was assessed in terms of Average weighted coherence (i.e., degree of entrainment between teacher and student cycles). Coherence (ranging from 0 to1) is a non-directional measure of entrainment and can be interpreted as the proportion of variance shared by the two time series. In Ethan's classroom, coherence was .88 for Communion and .85 for Agency. This indicates a considerable degree of entrainment (compare to $R^{2}$; large effect $=$ above .26 , Cohen, 1988, p. 414). In Sam's classroom, coherence was .14 for Communion and .13 for Agency. The degree of entrainment is much smaller than in Ethan's classroom (compare to $R^{2}$; medium effect = above .13, Cohen, 1988, p. 413).

Average weighted phase, represents the displacement of the teacher's peaks to the students' peaks in a time series, and can be interpreted as a lead-lag relationship, expressed as the fraction of a full cycle. Phase ranges from -0.5 to 0.5 ; values close to 0 indicate teacher and student cycles peak at the same moment and values closer to -0.5 and 0.5 indicate that the peaks are opposite. In terms of complementarity one could say that phase values close to 0 indicate sameness, and values closer to - .05 and .05 indicate oppositeness. Also, positive phase indicates the teacher leads, and a negative phase indicates that the students lead in the interaction.

For Ethan's classroom, phase for Communion was .02 and for Agency phase was .46. This implies sameness in Communion and oppositeness in Agency, and, that Ethan is leading in the interaction. For Sam's classroom, phase for Communion was .44 and for Agency phase was -.44. This implies oppositeness in both dimensions (which is similar to the overall coordination results described previously), and that Sam is leading in Communion (which underpins the idea that Sam is the catalyst of negative interactions) but is following in Agency.

\section{Random Variation}

To examine whether the teacher-student interactions could be described using the previous three analysis steps, the associations between random behaviors of teachers and students were studied. To do this, all trends and the cycles were removed from the time series, using autoregressive integrated moving average (ARIMA) modeling (Warner, 1998) and the lagged cross-correlation function (CCF) between teacher and student Communion and between teacher and student Agency was computed. We found very small correlations both for Ethan 
(For communion $\mathrm{CCF}=.02$, n.s.; for Agency CCF $=-.01$, n.s.) and for Sam (For communion $\mathrm{CCF}=-.08, \mathrm{p}<.05$; for Agency $\mathrm{CCF}=-.02$, n.s.), with no clear high points. This means that the dependence between teacher and student time series for Ethan's classroom on both dimensions and for Sam on the Agency dimension could very well be described looking at overall coordination, linear trends and cyclical patterns. For Sam's interactions with his students there is still a very small correlation on the Communion dimension. This indicates that there is still some kind of pattern left to describe which could be explored using further analyses.

\section{Discussion}

The aim of the present study was to show and explain the added value of looking at different steps in the analysis behavioral time-series data (i.e., observations of teacher and student behaviors) to study (a) the fit between teacher and student interpersonal behavior, and (b) differentiate between teachers with different interpersonal styles (i.e., Ethan with a desirable and Sam with a less desirable interpersonal style. The fit was described in terms of the principle of complementarity (e.g., Kiesler, 1996) at each step of the time-series analysis.

It is assumed that complementarity is related to good relationships (e.g., Kiesler, 1996). Yet, in some cases, interactions are not entirely following the principle of complementarity (Kiesler, 1996; Orford, 1986). Kiesler (1996) and Orford (1986) suggest that in hierarchical relationships, where one person has more status than the other, sometimes interactants refrain from complementarity to maintain a positive relationship. This may also be the case in educational settings, where teachers refrain from complementary reactions to hostile student behavior due to their professional role in the classroom (Thijs et al., 2011).

Given these assumptions, it was expected that Ethan's interactions with his students, in general, would be following the complementarity principle more than Sam's interactions, since Ethan's interpersonal style was more desirable than Sam's. It was also expected that because of their professional role and status, both teachers would be able to refrain from the principle of complementarity, especially in Communion, when faced with hostile and dominant student behavior.

\section{Complementarity}

Overall level

Looking at the overall level and coordination we saw that Ethan's interactions with student followed the complementarity principle on both dimensions. Ethan showed higher levels of Agency and Communion and his student showed lower levels of Agency and similar levels of Communion. This matches with what we theoretically expect, sameness on the Communion dimension and oppositeness on the Agency dimension. Sam's interactions with students were also consistent with this principle of complementarity. However, Sam's showed low levels of Agency and Communion and showed high levels of Agency and a similar level of Communion. Thus, although, in both classroom the average level followed the principle of complementarity, they were completely opposite in nature.

\section{Overall Coordination}

The cross-correlations representing the overall coordination or fit between the time-series showed a strong pattern of coordination that is consistent with the complementarity 
principle for Ethan, on both dimensions. For, Sam however, the cross-correlation indicated an a-complimentary pattern for Communion (oppositeness instead of sameness), and a very week pattern of complementarity for Agency (correlation was close to zero, but negative, indicating oppositeness, as expected).

\section{Trend}

For both teacher's and their students' behaviors changed throughout the lesson. This change could best be represented using a cubic model. For Ethan, these changes in levels of Agency were consistent with the principle of complementarity (changes in teacher and student communion were similar, and changes in agency were opposite; increasing for Ethan and decreasing for his students).

For Sam, again there was a different pattern. Showing an opposite pattern for Communion and a pattern of Sameness for Agency. Sam's interactions are characterized by a pattern of anti-complementarity.

\section{Cycles}

Both teacher's interactions where significantly represented by cyclical trends that were superimposed on the linear, quadratic, and cubic trends. For Ethan those cylces were strongly entrained, for Sam only moderately. For Ethan, the phase results showed he was leading in the interaction, and that the displacement in cycles showed sameness for Communion and oppositeness for Agency. For Sam, the phase results showed oppositeness in both dimensions, and that Sam was leading in Communion but following in Agency.

Concluding, these results show that indeed a pattern of complementarity was found in Ethan's interactions with his students, and that Sam's interactions with students were not following the complementarity principle, most of the time. In that sense, it seems that a desirable teacher interpersonal style (Wubbels et al., 2006) is indeed related to more complementarity in interactions.

\section{Refraining from complementarity}

It could be seen from the visual inspection of the time-series that Ethan and his students did not engage in unfriendly behavior. It could also be seen that Sam was not to be able to refrain from hostile behavior, and even seemed to be the catalyst of negative behavior (which seemed to be proved by the lead-lag relationship, represented by phase in Communion). Although in a recent study it was found that teachers with desired interpersonal styles were better able to refrain from hostile student behavior (Pennings, 2017), in this study, the hypothesis that both teachers can refrain from negative student behavior could not be confirmed. For Ethan, because he simply did not face hostile student behavior, while for Sam, it might be the case that he is struggling so much to get his students' attention that he cannot think of remaining friendly.

\section{Limitations and Future Directions}

In the present study, only two teachers were studied, thus the goal was not generalizability. The teachers in the present study were early career teachers. Studying the interactions of more teachers with different interpersonal styles and also in different stages of their career, may be necessary to formulate advice that could be used in practice. 
Also, the most important premise of interpersonal theory is that all interpersonal behavior should be described in terms of the combination of Agency and Communion. Although Agency and Communion were observed simultaneously, is was not possible to analyze them as one variable, because current methods do not allow for the analysis of both dimensions combined. Circular statistics (Batschelet, 1981; Berens, 2009) is a method that may be suitable, but is still in its infancy and needs further development (Berens, 2009) before it can be used in this kind of research. In the future, the possibilities of using circular statistics should thus be explored, so that the interplay of Agency and Communion can also be considered.

In the present study, the whole class was observed to address dynamics at the class level, instead of observing students individually or in small groups. Although, the teacherclass interaction is a typical example of a one-with-many interaction (Kenny et al., 2006), observing individual students would provide an additional layer of information about individual teacher-student dynamics in the classroom. For example, observations of withinclassroom interactions of the teacher and individual students with whom they indicate they have either a positive or a problematic relationship (c.f. Claessens et al., 2016), may be very informative, or interactions with individual students that stand out during the interaction.

In addition to the observation of individual students' behavior, instead of only including the teacher's interpersonal style, future research should take into account the quality of all dyadic relationships in a classroom (i.e., reciprocal teacher-student and peer-peer perceptions), to assess how the variance in interpersonal perceptions is divided between as well as within dyads in classrooms, e.g., using the actor-partner interdependence models (APIM; Kenny et al., 2006).

\section{Practical Implications}

Formulating practical implications of this study presupposes causality, which is not evidenced. Therefore, I here formulate only a general suggestion that might aid in designing teacher education and in-service professional developmental trajectories, especially when video guided coaching is used.

The findings of the present study show that it is not always good to rely on generalized findings. To help individual teachers improving their teaching practice, their teaching practice should be observed, for example, using such fine grained observations and analysis as done in this study.

Interaction of teachers with students in classrooms can be used strategically, but is often also an automatic process. Becoming aware of potential (in) effective interaction strategies or patterns and learning about possible directions to change may be a first step towards improvement. For example, observing both real-time teacher and student behavior during coaching sessions provides opportunities to analyze the fit and interrelatedness of their own behavior with their students' behavior. This may help teachers to understand why they experience problems in establishing positive relationships with students.

\section{References}

Batschelet, E. (1981). Circular statistics in biology. London: Academic Press.

Berens, P. (2009). CircStat: A MATLAB toolbox for circular statistics. Journal of Statistical Software, 31(10),

1-21. Retrieved from http://kyb.mpg.de/fileadmin/user_upload/files/publications/attachments/J-StatSoftw-2009-Berens_6037\%5b0\%5d.pdf 
Claessens, L., Van Tartwijk, J., Pennings, H., Van der Want, A., Verloop, N., Den Brok, P., \& Wubbels, T. (2016). Beginning and experienced secondary school teachers' self-and student schema in positive and problematic teacher-student relationships. Teaching and Teacher Education, 55, 88-99. doi:http://dx.doi.org/10.1016/j.tate.2015.12.006

Cohen, J. (1988). Statistical Power Analysis for the Behavioural Sciences, 2d Edition, Hillsdale, N.J.: Lawrence Erlbaum Assocs. Inc.

Granic, I., \& Hollenstein, T. (2003). Dynamic systems methods for models of developmental psychopathology. Development and Psychopathology, 15(3), 641-669. doi:10.1017.S0954579403000324

Grassi, M., Luccio, R., \& Di Blas, L. (2010). CircE: An R implementation of Browne's circular stochastic process model. Behavior Research Methods, 42(1), 55-73. doi:10.3758/BRM.42.1.55

Gurtman, M. B. (2011). Circular reasoning about circular assessment. In L. M. Horowitz \& S. Strack (Eds.), Handbook of interpersonal psychology (pp. 209-312). New York: Wiley.

Hollenstein, T. (2007). State space grids: Analyzing dynamics across development. International Journal of Behavioral Development, 31, 384-396. doi: 10.1177/0165025407077765

Hollenstein, T. (2013). State space grids: Depicting dynamics across development. New York: Springer.

Horowitz, M. L., \& Strack, S. (2011). Handbook of interpersonal psychology. New York: Wiley.

Kenny, D. A., Kashy, D. A., \& Cook, W. L. (2006). Dyadic data analysis. New York: The Guilford Press.

Kiesler, D. J. (1996). Contemporary interpersonal theory and research. New York: Wiley.

Koopmans, M., \& Stamovlasis, D. (2016). Complex Dynamical Systems in Education: Concepts, Methods and Applications. New York: Springer. doi:10.1007/978-3-319-27577-2

LeBreton, J. M., \& Senter, J. L. (2008). Answers to twenty questions about inter-rater reliability and interrater agreement. Organizational Research Methods, 11, 815-852. doi:10.1177/1094428106296642

Lizdek, I., Woody, E., Sadler, P., \& Rehman, U. S. (2016). How do depressive symptoms in husbands and wives relate to the interpersonal dynamics of marital interactions? Journal of Counseling Psychology, 63(6), 721-735. doi:10.1037/cou0000167

Locke, K. (2011). Circumplex measures of interpersonal constructs. In L. M. Horowitz \& S. Strack (Eds.), Handbook of interpersonal psychology (pp. 313-324). New York: Wiley.

Lüdtke, O., Robitzsch, A., Trautwein, U., \& Kunter, M. (2009). Assessing the impact of learning environments: How to use student ratings of classroom or school characteristics in multilevel modeling. Contemporary Educational Psychology, 34, 120-131. doi:10.1016/j.cedpsych.2008.12.001

Orford, J. (1986). The rules of interpersonal complementarity: Does hostility beget hostility and dominance, submission? Psychological Review, 93, 365-377.

Pennings, H. J. M. (2017). Interpersonal dynamics in teacher-student interactions and relationships. Enschede: Ipskamp Printing.

Pennings, H. J. M., Brekelmans, M., Wubbels, T., Van Der Want, A. C., Claessens, L. C. A. \& Van Tartwijk, J. (2014). A nonlinear dynamical systems approach to real-time teacher behavior: Differences between teachers. Nonlinear Dynamics, Psychology, and Life Sciences, 18(1), 23-45.

Pincus, A. L., Sadler, P., Woody, E., Roche, M. J., Thomas, K., \& Wright, A. G. C. (2014). Multimethod assessment of interpersonal dynamics. In C. J. Hopwood \& R. F. Bornstein (Eds.), Multimethod clinical assessment (pp. 51-91). New York: Guilford.

Ramseyer, F., \& Tschacher, W. (2016). Movement coordination in psychotherapy: Synchrony of hand movements is associated with session outcome. Nonlinear Dynamics, Psychology, and Life Sciences, 20(2), 145-166.

Roorda, D. L., Koomen, H. M. Y., Spilt, J. L., Thijs, J. T., \& Oort, F. J. (2013). Interpersonal behaviors and complementarity in interactions between teachers and kindergartners with a variety of externalizing and internalizing behaviors. Journal of School Psychology, 51, 143-158. doi:10.1016/j.jsp.2012.12.001

Sadler, P., Ethier, N., Gunn, G. R., Duong, D., \& Woody, E. (2009). Are we on the same wavelength? Interpersonal complementarity as shared cyclical patterns during interactions. Journal of Personality and Social Psychology, 97(6), 1005-1020. doi:10.1037/a0016232

Thijs, J. T., Koomen H.M.Y., Roorda, D. L., \& Ten Hagen, J. (2011). Explaining teacher-student interactions in early childhood. Journal of Applied Developmental Psychology pp. $34 \quad-\quad 43$. doi:http://dx.doi.org/10.1016/j.appdev.2010.10.002

Warner, R. M. (1991). Incorporating time. In B. M. Montgomery \& S. Duck (Eds.), Studying

interpersonal interaction (pp.82-102). London: Guilford Press. 
Warner, R. M. (1998). Spectral analysis of time-series data. New York: Guilford.

Wubbels, T., Brekelmans, M., Den Brok, P., \& Van Tartwijk, J. (2006). An interpersonal perspective on classroom management in secondary classrooms in the Netherlands. In C. Evertson \& C. Weinstein (Eds.), Handbook of classroom management: Research practice and contemporary issues (pp. 11611191). New York: Lawrence Erlbaum Associates.

\section{Acknowledgement}

This work was supported by the Netherlands Organization for Scientific Research, NWO/PROO [grant number 411-07-363]

\section{About the Author}

Dr. Helena J. M. Pennings works as a postdoctoral researcher at Utrecht University in the Netherlands. Her research interests are the interpersonal dynamics in interactions and relationships. Currently her research if focused especially on the interactions between teachers and students and how interactional processes are related to the quality of the teacher-student relationships. Correspondence should be addressed to Helena Pennings, Utrecht University, PO Box 80.140, 3508 TC Utrecht, The Netherlands. E-mail: H.J.M.Pennings@uu.nl.

\footnotetext{
(c) Copyright 2017. The author, HELENA PENNINGS, assigns to the University of Alberta and other educational and non-profit institutions a non-exclusive license to use this document for personal use and in courses of instruction provided that the article is used in full and this copyright statement is reproduced. The authors also grant a non-exclusive license to the University of Alberta to publish this document in full on the World Wide Web, and for the document to be published on mirrors on the World Wide Web. Any other usage is prohibited without the express permission of the authors.
} 